\title{
Molecular Diagnosis of Chronic Myeloid Leukemia \& Monitoring Response to Different Types of Treatment
}

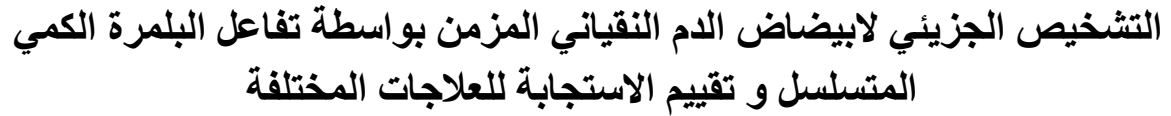

Amina Nimma Al-Thwaini

Manal Ali Abdul-Sahib*

Aladdin Mudhafar Zubair Al-Qasim **

Institute of Genetic Engineering \& Biotechnology/ Baghdad University

* National Center of Hematology/Al-Mustansirya University

**College of Medicine/ Al- Mustansirya University

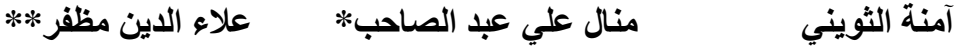

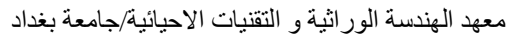

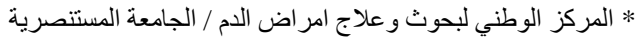

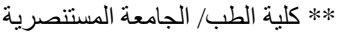

\section{Abstract}

Q

hronic myeloid leukemia (CML) is one of leukemia types which account for $15 \%$ to $20 \%$ of all leukemia cases. Patients are presented with splenomegaly, fever, anemia, fatigue, weight loss, and weakness. It is results from reciprocal translocation $(9 ; 22)$.This abnormality is called Philadelphia (Ph) chromosome and it is detected in $95 \%$ of patients with CML, and in $20 \%$ of patients with Acute Lymphocytic Leukemia (ALL). "Imatinib mesylate" is the most widely used drug for CML treatment because it targets the abnormal fusion gene. Blood samples were collected from (39) CML patients (19 males and 20 females) from July - November 2009 in The National Center of Hematology/Baghdad. The age range were $(8-70)$ years. According to the real time PCR results; the patients were divided into four groups: 1) PCR negative group. 2) PCR positive group on Hydroxyurea treatment 3) PCR positive group on Gleevec ${ }^{\circledR}$ treatment 4) PCR positive group with no treatment (recently diagnosed). Patients were selected randomly. Their RNA was extracted from peripheral blood cells and reverse transcribed into cDNA which was amplified using real time PCR to measure the ratio of BCR-ABL fusion gene in their Philadelphia chromosome. This is to confirm the diagnosis and evaluate the response to the most widely used drugs for CML treatment (Gleevec ${ }^{\circ} 400 \mathrm{mg} / \mathrm{d}$ and hydroxyurea $450 \mathrm{mg} / \mathrm{d}$ for two months at least). This study excluded CML diagnosis in 10 patients, so other myeloproliferative disorders need to be verified. The group treated with Gleevec ${ }^{\circledR}$ showed a better response than hydroxyurea at the molecular level. Key words: leukemia, chronic myeloid leukemia, polymerase chain reaction, real time $\mathrm{PCR}, \mathrm{BCR}-\mathrm{ABL}$, quantitative $\mathrm{PCR}$, hydroxyurea, imatinib mesylate, Philadelphia chromosome, tyrosine kinase.

\footnotetext{
المستخلص

ابيضاض الدم النقياني المزمن هو أحد أنواع سرطانات الام وهذا المرض مسؤول عن 15 20\% من حالات

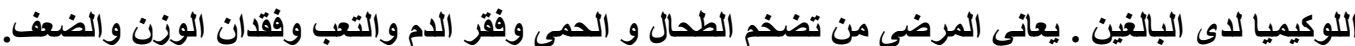
بتتج المر ضر من تبادل بين الكروموسومين (9 ،22) ـ يسمى هذا الشذوذ كروموسوم فيلادلفيا و هو موجود ماض الام النقياني المزمن ، تفاعل البلمرة المتسلسل ، الهيدروكسي يوريا ، الكليفك ، كروموسوم فيلادلفيا 


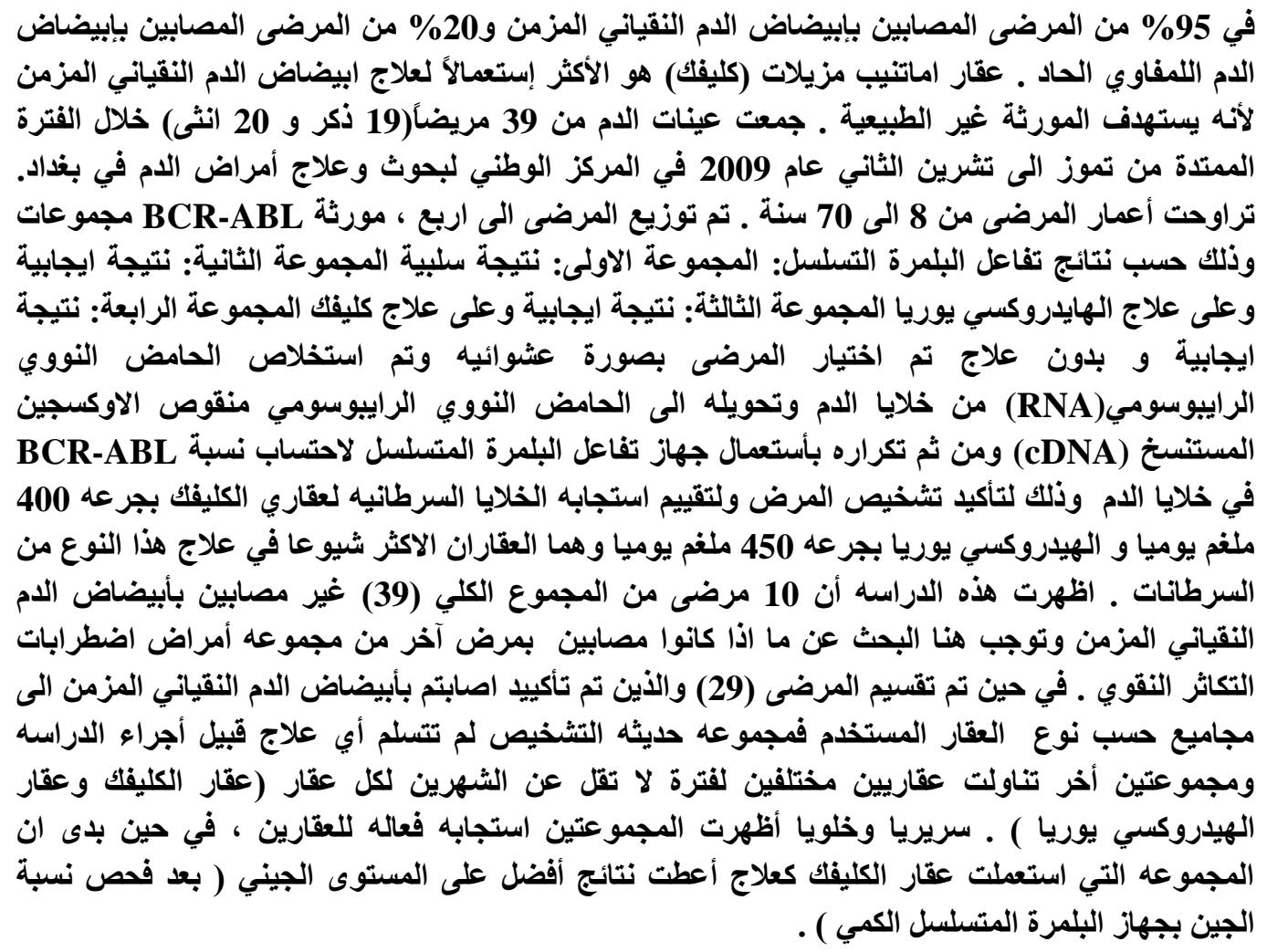

\section{Introduction}

Chronic myeloid leukemia (CML) is one of leukemia types which accounts for $(15,20) \%$ of all leukemia cases [1]. Manifested clinically as a marked increase in granulocytes, bone marrow hyperplasia, and splenomegaly [2], fever, anemia, fatigue, weight loss, and weakness [3].

Chronic myeloid leukemia is associated with the presence of Philadelphia (Ph) chromosome, detectable microscopically, which results from reciprocal translocation $(9 ; 22)$ [4]. The Philadelphia $(\mathrm{Ph})$ chromosome abnormality is detected in $95 \%$ of patients with CML, and in $20 \%$ of patients with Acute Lymphocytic Leukemia [5].

The real time PCR is important in CML diagnosis because it has the ability to detect the BCR-ABL fusion gene which is a constitutively active tyrosine kinase, a feature that is critical to the protein's ability to induce leukemia and provides the rational basis for Abl kinase targeted therapy of Ph-positive Leukaemias with Abl kinase inhibitors.

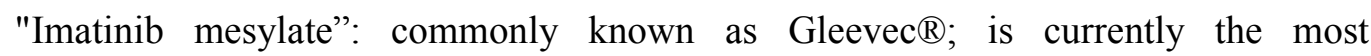
efficacious, target-specific drug for the treatment of CML [6] Gleevec $₫$ binds ATPbinding site of tyrosine kinase domain, protein trigger the carcinogenic pathway, thus, by occupying and blocking the ATP-binding site resulting in prevention of the signal transduction leading to the onset of CML[7].

\section{Objectives}

The objectives of current study are:

Use of real time PCR to detect BCR-ABL fusion gene in the blood sample of CML patients to ensure their diagnosis. Comparison between the responses of different medication types used in CML treatment. 


\section{Subjects}

Blood samples of (39) Iraqi patients (19 males, 20 females) were collected. Their age range was $(8-70)$ years. They were out-patients in the National Center of Hematology/ Baghdad/ Iraq. The study was conducted during July- November 2009. Provisional diagnosis was made by the consultant physician in the center and it was confirmed by a laboratory blood and bone marrow examination.

Those patients were divided into two groups:

* The first group included 10 patients who were suspected cases of CML. They did not receive any medication till the date of this study and underwent RT-PCR to confirm the diagnosis (control group).

* The second group included 29 patients with a proved diagnosis of chronic myeloid leukemia (CML) and did the RT-PCR to measure the ratio of BCR/ABL fusion gene to ensure their diagnosis for first reading and to estimate the response to treatment by repeating the investigation every three months.

\section{The second group is subdivided into three subgroups:}

1. Nine patients who were treated by Gleevec ${ }^{\circledR}$ tab $400 \mathrm{mg} /$ day for more than 3 months.

2. Ten patients who were treated by hydroxyurea tab $450 \mathrm{mg} /$ day for more than 3 months.

3. Ten patients who received no treatment at the time of blood sampling for RT-PCR.

\section{Methods}

\section{Total RNA isolation}

Two milliliters of peripheral blood were taken into EDTA coated tubes and transmitted within $(2-4)$ hours. By micropipette $0.25 \mathrm{ml}$ of blood sample was taken in an eppendorf tube that containing $0.75 \mathrm{ml}$ of one step RNA reagent then mixed well for 1 minute. The homogenized sample Incubated for 5 minutes at $20^{\circ} \mathrm{C}$ to permit the complete dissociation of nucleoprotein complexes. Chloroform (0.2) $\mathrm{ml}$ was added to the tube. Shaked vigorously by hand for 15 seconds and incubated at $20^{\circ} \mathrm{C}$ for 4 minutes.

The samples were centrifuged at 12000 rounds per minute (rpm) for 15 minutes at $4{ }^{\circ} \mathrm{C}$. The centrifugation separates the mixture into a lower phenol-chloroform phase, a cloudy white interphone and a colorless upper aqueous phase. The volume of the aqueous phase is about $60 \%$ of the volume of the mixture and the RNA remains exclusively in the aqueous phase.

The aqueous phase was transferred by micropipette to a fresh clean labeled tube and the RNA was precipitated from the aqueous phase by mixing with $0.5 \mathrm{ml}$ isopropanolol alcohol. Samples were incubated at $4^{\circ} \mathrm{C}$ for 30 minutes then centrifuged at $12000 \mathrm{rpm}$ for 10 minutes at $2-8^{\circ} \mathrm{C}$. The supernatant was removed and the RNA pellet washed with $0.5 \mathrm{ml}$ of $75 \%$ ethanol. The tube was gently inverted several times to wash the mixture pellet at the side of the tube, then centrifuged at $12000 \mathrm{rpm}$ for 10 minutes at $2-8^{\circ} \mathrm{C}$.

The ethanol was carefully aspirated. The mixture pellet was very loose at that point; therefore, care must be taken to avoid aspirating the pellet into the pipette. The tube was inverted on clean absorbent paper and air-dried the pellet for about 
so briefly the RNA pellet was dried (it is important not to let the RNA pellet dry completely as this will greatly decrease its solubility). The RNA was re-dissolved at the end of procedure by adding $50 \mu \mathrm{l}$ of distilled water acting. Then stored at $(3-8)^{\circ} \mathrm{C}$ for more than 1 month till other sample collected.

\section{Agarose gel electrophoresis (Electrophoresis of DNA)}

The extracted RNA was run on agarose gel electrophoresis to confirm the presence and integrity of the extracted RNA. The samples were run using $404 \mathrm{mAmp}$ and 65 volts for 60 minutes. The bands were visualized under UV transilluminator at $350 \mathrm{~nm}$.

[8]

\section{cDNA Synthesis}

\section{Preparation of solution A}

A labeled tube for each patient's sample was prepared. Each contains $3 \mu 1$ of patient's RNA sample, $1 \mu 1$ of Random Primer, $1 \mu 1$ of dNTPs and finally $8 \mu 1$ of distilled water. So the total volume is $13 \mu \mathrm{L}$ in each tube.

\section{Preparation of solution $B$}

Four $\mu \mathrm{l}$ of Buffer solution, $1 \mu \mathrm{l}$ of Dithiothreitol (DTT), $1 \mu \mathrm{l}$ of RNase and $1 \mu 1$ of RTase were added to each labeled tube which already contain $13 \mu \mathrm{L}$ of solution A. So the total volume now will be $20 \mu \mathrm{l}$ of both solutions A and B in each tube.

All the samples have been incubated in $50^{\circ} \mathrm{C}$ for 50 minutes .Then in $70^{\circ} \mathrm{C}$ for further 15 minutes. Then thirty microliters of distilled water were added to each tube to complete the volume to $50 \mu \mathrm{L}$. Then tubes were stored in a deep freeze.

\section{Real time PCR}

The BCR-ABL kits (Ipsogen, France) contain several substances divided mainly in two groups

1.Fusion gene group: includes 5 tubes of fusion gene and one negative control tube. These tubes are labeled (F1-F6). Corresponding Eppendorf tubes are labeled F1-F6 also. The following is added to these tubes: $12.5 \mu 1$ of Taq man, $1 \mu 1$ of Primer of FG and $6.5 \mu \mathrm{l}$ of distilled water to each one of these six tubes.

2.The Control gene group: consists of 3 control gene tubes and one negative control tube labeled (C1-C4). Corresponding Eppendorf tubes are labeled (C1-C4) to which $12.5 \mu 1$ of Taq man, $1 \mu 1$ of CG Primer and $6.5 \mu 1$ of distilled water were added to each one of these 4tubes.

Then:

- Five microliter of cDNA of the patient was added to patient tubes of both fusion gene and control gene tubes which were prepared previously.

- Five microliter of fusion gene was added to their 5 fusion gene tubes.

- Five microliter of control fusion gene was added to their 3 control gene tubes.

- Five microliters of distilled water was added to negative control tube of both fusion gene and control gene tubes.

The run entered to the PCR machine on real time PCR program (iCycler program).

The result appears as ratio of both F.G. and C.G.

So the final ratio $=($ F.G. ratio $/$ C.G. ratio $) * 100$ 


\section{Results:}

Table (1) shows the distribution of patients according to gender. Table (2) shows the mean age for each subgroup of patients. Tables (3) and 4 demonstrate the ratio and $\log$ of PCR results, respectively. The duration of each type of treatment is clarified in Table (5).

Table (1): distribution of four groups of patients according to gender

\begin{tabular}{lllllll}
\hline & \multicolumn{4}{l}{ Sex } & & \\
& No. & Males & \multicolumn{2}{c}{ Females } \\
Group of patient & & No & $\%$ & No & $\%$ \\
PCR negative & 10 & 3 & $\mathbf{3 0 . 0}$ & $\mathbf{8}$ & $\mathbf{7 0 . 0}$ \\
PCR positive on treatment HU* & 10 & 5 & $\mathbf{5 0 . 0}$ & $\mathbf{5}$ & $\mathbf{5 0 . 0}$ \\
PCR positive on treatment Gleevec & 9 & 6 & $\mathbf{6 6 . 7}$ & $\mathbf{3}$ & $\mathbf{3 3 . 3}$ \\
PCR positive No treatment & $\mathbf{1 0}$ & 7 & $\mathbf{7 0 . 0}$ & $\mathbf{3}$ & $\mathbf{3 0 . 0}$ \\
Total patients number & 39 & & & & \\
\hline
\end{tabular}

*HU= hydroxyurea

Table (2): mean of age of each patients group of leukemic patients

\begin{tabular}{lll}
\hline & Age (years) & \\
PATIENTS GROUP & Mean \pm SD & Range \\
PCR negative & $45.73 \pm 18.19$ & $16.00-70.00$ \\
PCR positive on treatment HU & $49.00 \pm 13.82$ & $\mathbf{2 6 . 0 0 - 6 5 . 0 0}$ \\
PCR positive on treatment Gleevec & $41.67 \pm 9.72$ & $30.00-60.00$ \\
PCR positive No treatment & $29.90 \pm 13.79$ & $\mathbf{8 . 0 0 - 5 7 . 0 0}$ \\
\hline
\end{tabular}

Table (3): mean and range for the ratio of PCR result for all groups

\begin{tabular}{lll}
\hline & Ratio & \\
Leukemic group patients. & Mean \pm SD & Range \\
PCR negative & - & - \\
PCR positive on treatment HU & $0.354 \pm 0.385$ & $(0.080-1.120)$ \\
PCR positive on treatment Gleevec & $0.294 \pm 0.464$ & $(0.014-1.500)$ \\
PCR positive No treatment & $1.547 \pm 1.643$ & $(0.080-5.200)$ \\
\hline
\end{tabular}

Table (4) mean and range for the log of PCR result for all groups

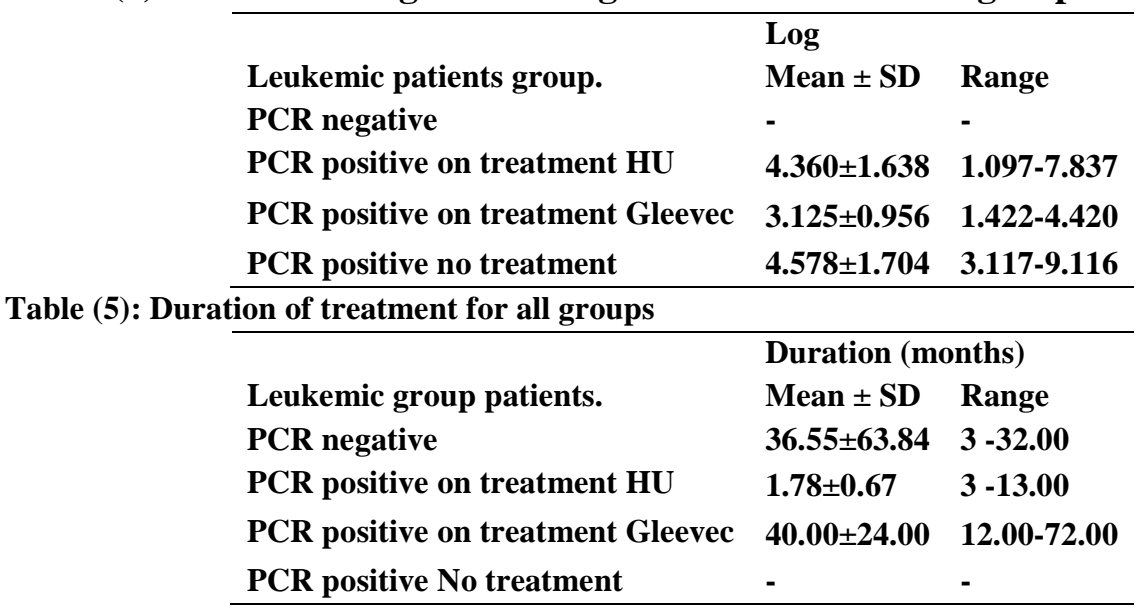




\section{Discussion}

The real time PCR provides an accurate, sensitive, and noninvasive measure of residual leukemia in patients on imatinib. Levels of BCR-ABL in the blood cells correlate with the bone marrow cytogenetic results and early measurement can predict subsequent cytogenetic response [9].

Quantitative (RT-PCR) was performed using peripheral blood cells. According to the results, eleven patients were free of the abnormal BCR-ABL gene in spite of previous diagnosis as CML by their hematological picture. So they were considered as a control group. The rest of patients who had ratio result for fusion gene were divided into 3 groups according to their type of treatment: Gleevec ${ }^{\circledR}$ or hydroxyurea for more than 2 months and the last group received no medication as they were recently diagnosed.

The patients were categorized according to their response to the drugs, by assessing the Q-PCR result after more than 3 months of treatment of each line (Gleevec ${ }^{\circledR}$ and H.U.).

Significant difference was found in patients' gender because $62.1 \%(18 / 29)$ of the confirmed diagnosis of CML patients were males while $37.9 \%(11 / 29)$ were females, as shown in Table (1).

The overall ratio of male: female in this study was $(2: 1)$. CML shows a slight male predominance, with a male to female ratio 3:2 [10]. This small difference between the ratios may be attributed to the small number of cases involved in this study. However, it is in agreement with Dhahii study which concluded that male to female ratio was (1.62:1) [11].

The range of age of the cases was between ( 8 -70) years as shown in Table (2). The mean age of PCR positive cases on HU was 47.8 years and the mean age of PCR positive cases on Gleevec $\AA$ was 41.67 years. The mean age of PCR positive cases with no treatment was 29.90 years. Thus the overall mean age of CML cases was 39.79 years which is comparable to Dhahii study which found that the CML mean age equal to 32.83 years. [11] Goldman presented the fact that CML affected the old age and may be attributed to the loss of the genetic material with each cell division. [12] In addition to, the accumulation of carcinogenic chemicals which increase with the age. Harvey referred also to the mutant effect of exposure to benzene and to other products in increasing the incidence of CML [13].

Table (3) shows that the PCR (-ve) group of patients are not actually CML cases or they might have blood disorders other than CML. Therefore; they must be investigated further. This group was considered as a control group. The highest ratio value (5.200) was obtained in patients receiving no treatment with a range (0.0805.200 ) and a mean of (1.547). This ratio indicates the presence of large number of abnormal leucocytes in the blood sample. The lowest (+ve) ratio result $(0.014)$ appears in CML patients treated by Gleevec ${ }^{\circledR}$ with a range $(0.014-1.500)$ and a mean of (0.294). This is expected because the drug produces remission at the molecular level. That is why it is the first line of treatment in CML. This means that a low number of abnormal cells in the peripheral blood and better response. This conclusion is in agreement with [14] study about cytogenetic analysis and DN. 
blood cells from some patients with chronic myeloid leukemia in Baghdad and concluded that Gleevec ${ }^{\circledR}$ gave a better response than HU with the same duration of treatment. Patients treated with HU showed an intermediate range result (0.080-1.120) with a mean of (0.354).

The result of log reading data in Table (4) is similar to the ratio result data since a better response to treatment was obtained in CML patients treated with Gleevec ${ }^{\circledR}$ which is less than the log reading for CML group treated with H.U. These results explain that the complete hematological response (CHR) with Gleevec ${ }^{\circledR}$ treatment was $100 \%$ and the major cytogenetic response (MCR) was 33\%. Andreas study which included 227 American CML patients showed that CHR was also 100\% but the MCR was only $21 \%$ [15].

The higher log reading value (9.116) was obtained in patients receiving no treatment with a mean of (4.578) and range of (3.117-9.116). The lowest value (4.420) is noted in patients treated by Gleevec ${ }^{\circledR}$ with a mean of (3.125) and rang of (1.422-4.420) .The patients who were treated with HU showed an intermediate response ranging from (1.097-7.837) with mean log reading value of (4.360) and the maximum result was (7.837), so those data are consistent with the previous ratio result .

The duration as well as the well follow up is so important to get the best response and save the patient's life.

Table (5) shows that the zero duration of treatment related to newly diagnosed patients group while the longer one belongs to CML patients treated with Gleevec $₫$ so this explains that it prolongs the patient's life more than H.U. The difference of treatment duration affects negatively the efficiency of PCR and also on the assessment of patients' response to treatment. Therefore; all experts advise to perform PCR at time of diagnosis then every 3 months during the treatment course. ${ }^{[16]}$ The PCR negative groups have also long duration of treatment as they have non-fatal haematological disease.The longer duration of treatment was found in PCR positive groups on Gleevec ${ }^{\circledR}$ with mean of (40.0) months compared to shorter duration in those patients on HU with mean of (1.78) months. It must be due to the lower response to the 2 nd drug so the physician would change the line of treatment to the Gleevec $®$ or the patient may pass after several months of diagnosis.

\section{References:}

1. Deininger M.; (2007) BCR-ABL as a Molecular Target. In: Cortes J and Deininger M, editors. Chronic Myeloid leukemia. New York: Informa Healthcare.

2. Goldman JM, Gordon MY. (2006) Why do stem CML cells survive allogeneic stem cell transplantation or imatinib? Does it really matter? Leukemia and Lymphoma; 47:1-8.

3. Kantarjian HM, O’Brien S, Cortes JE, Smith TL, Rios MB, Shan J et al.(2002) Treatment of Philadelphia chromosome-positive, accelerated-phase chronic myelogenous leukemia with imatinib mesylate. Clin Cancer Res; 8(7):2167-2176.

4. Nowell PC and Hungerford DA. (1960) A minute chromosome in human chronic granulocytic leukaemia. Science; 132:1497.

5. Kantarjian HM, Pierce $S$ and Kaled S. (1999) Treatment of chronic myeloid leukemia in different phase with STI571. Leuk Insights; 4(4): 1-7. 
6. Deininger $\mathrm{M}$ and Druker BJ. (2003) Specific targeted therapy of chronic myelogenous leukemia with imatinib. Pharmacol Rev; 55(3):401-423.

7. Talpaz M, Silver RT, Druker BJ, Goldman JM, Gambacorti-Passerini C, Francois Guilhot F et al. (2002) Imatinib induces durable hematologic and cytogenetic responses in patients with accelerated phase chronic myeloid leukemia: results of a phase 2 study. Blood; 99(6): 1928-37.

8. Sambrook J \& Maniatis T. (1989) Molecular cloning: a laboratory manual. Second edition. New York: Cold Spring Harbor Laboratory Press;.

9. Al-Shammary SA. (2006). Statistical and cytogenetic study on chronic myeloid leukemia patient in Iraq. Diploma Thesis. The Institute of Genetic Engineering and Biotechnology, Baghdad University, Iraq.

10. Gunz FW. (1977). The epidemiology and genetics of the chronic leukemias. Clinical Haematology; 6: 3-20.

11. Dhahii MA. (2008). Molecular, cytogenetic and immunological detection and quantification of BCR-ABL gene and protein in Chronic Myeloid Leukemia patients treated with Imatinib. Ph.D. thesis. Al- Nahrain University: College of Medicine.

12. Goldman JM (1998). Leukemia and related disorders. Third edition. London: Blackwell Science. p. 235-267.

13. Harvey RG. (1991). Polycyclic Aromatic Hydrocarbons Chemistry and Carcinogenicity. New York: Cambridge University Press. p. 113-128.

14. AL-Neimy SH. (2006) Cytogenetic analysis and DNA estimation of blood cells from some patients with chronic myelocytic leukemia in Baghdad. M.SC. thesis. AL-Nahrain University: College of Science.

15. Petzer AL, Wolf D, Fong D, Lion T, Dyagil I, Masliak $Z$ et al. (2007). Multicenter, Randomized, Phase III Study Comparing Imatinib (Glivec) Standard Dose $(400 \mathrm{mg} / \mathrm{d})$ with Imatinib High Dose Induction $(800 \mathrm{mg} / \mathrm{d})$ Followed by Imatinib Maintenance $(400 \mathrm{mg} / \mathrm{d})$ in Patients with Pretreated $\mathrm{Ph}^{+} / \mathrm{BCR}-\mathrm{ABL}^{+} \mathrm{CML}$ in Chronic Phase - Results from the First Planned Interim Analysis (CELSG-CML 11 ISTAHIT Study). Blood (ASH Annual Meeting Abstracts), 110(11): 1048.

16. Middle East CML Forum 2008 Mar, Amman, Jordan. Novartis Oncology. 